\title{
Improving lifestyles sustainability through community gardening: results and lessons learnt from the JArDinS quasi-experimental study
}

Marion Tharrey ${ }^{1 *}$, Ashby Sachs², Marlène Perignon ${ }^{1}$, Chantal Simon ${ }^{3}$, Caroline Mejean ${ }^{1}$, Jill Litt ${ }^{2,4}$ and Nicole Darmon ${ }^{1}$

\begin{abstract}
Background: Despite an increasing number of studies highlighting the health benefits of community gardening, the literature is limited by cross-sectional designs. The "JArDinS" quasi-experimental study aimed to assess the impact of community garden participation on the adoption of more sustainable lifestyles among French adults.

Methods: Individuals entering a community garden in Montpellier (France) in $2018(n=66)$ were compared with pairwise matched individuals with no experience in community gardening $(n=66)$. Nutritional quality, environmental impact and cost of monthly household food supplies, level of physical activity measured by accelerometers, as well as mental and social well-being, sensitivity to food waste, and connection with nature were evaluated at baseline (t0) and 12 months later ( $\mathrm{t} 1$ ) to explore sustainability of lifestyles in social/health, environmental and economic dimensions. Linear mixed models were used to determine the independent effect of community gardening on investigated lifestyles components. In-depth interviews were conducted at t1 with 15 gardeners to better understand changes that may have occurred in gardeners' lives during the first year of gardening.

Results: At t0, gardeners had lower education level, lower BMl and their household reported lower percentage of meals consumed outside of the home compared to non-gardeners $(p<0.05)$. Participating in the community garden had no significant impact, in spite of sufficient statistical power, on fruit and vegetables supplies (main outcome), nor on physical activity parameters, nor on others of the social/health, environmental and economic lifestyles components investigated. Qualitative interviews suggested the existence of pre-established health and environmental consciousness in some gardeners and revealed several barriers to the participation such as lack of time, lack of gardening knowledge, physical difficulty of gardening, health problems and conflicts with other gardeners.
\end{abstract}

(Continued on next page)

\footnotetext{
* Correspondence: mariontharrey@hotmail.fr

'MOISA, Univ Montpellier, CIRAD, CIHEAM-IAMM, INRAE, Institut Agro, Montpellier, France

Full list of author information is available at the end of the article
}

(c) The Author(s). 2020, corrected publication 2020. Open Access This article is licensed under a Creative Commons Attribution 4.0 International License, which permits use, sharing, adaptation, distribution and reproduction in any medium or format, as long as you give appropriate credit to the original author(s) and the source, provide a link to the Creative Commons licence, and indicate if changes were made. The images or other third party material in this article are included in the article's Creative Commons licence, unless indicated otherwise in a credit line to the material. If material is not included in the article's Creative Commons licence and your intended use is not permitted by statutory regulation or exceeds the permitted use, you will need to obtain permission directly from the copyright holder. To view a copy of this licence, visit http://creativecommons.org/ licenses/by/4.0/. The Creative Commons Public Domain Dedication waiver (http://creativecommons.org/publicdomain/zero/1. $0 /$ applies to the data made available in this article, unless otherwise stated in a credit line to the data. 
(Continued from previous page)

Conclusions: The health benefits of community gardening previously reported by cross-sectional studies might be confounded by selection bias. The JArDinS study highlights the need to identify solutions to overcome barriers related to community garden participation when designing relevant public health interventions for the promotion of sustainable lifestyles.

Trial registration: The study was registered at clinicaltrials.gov as NCT03694782. Date of registration: 3rd October 2018, retrospectively registered.

Keywords: Quasi-experiment, Health promotion, Food supply, Nutrition, Physical activity, Accelerometer, Well-being, Connection to nature, Urban garden, Mental health

\section{Background}

In recent years an increasing body of literature has suggested that gardening could address various public health concerns through its positive effects on nutrition, physical activity, social cohesion, quality of life, stress and depression [1]. Beyond evidence drawn from gardening programs within institutions such as schools or health care settings [2-5], less is known about the potential health effects of urban collective gardening on free-living adults. Collective gardens, defined as cultivated spaces managed collaboratively by groups of gardeners located at a distant place from gardeners' homes, generally take the form of community or allotment gardens [6]. While allotments are large plots of lands usually located in peri-urban areas, rented to a person or a family for cultivation purposes [7, 8], community gardens are smaller plots of land usually integrated in the fabric of urban neighbourhoods, grown collectively [9]. The cost of the annual subscription varies from a hundred euros to a few euros, depending on the type of garden (allotment or community) and the type of land (private or public). Primarily intended to favour social links and intergenerational exchanges among the inhabitants of a neighbourhood, community gardens are a popular way to engage with green spaces, as they provide urban dwellers an avenue to access nature and safe and healthy food. Pathways through which community gardens could amplify individual health include intrapersonal, interpersonal and environmental processes, such as self-efficacy, attitudes, motivation, social support, neighbourhood attachment or aesthetic [10]. Yet, while several studies have shown a positive association between community gardening and fruit and vegetable consumption [11-15], inconclusive results were found for BMI [15-18], physical activity [12, 15], social health $[12,14,15,19,20]$ and mental well-being $[12$, 15]. The lack of conclusive evidence regarding differences in health related behaviors and health status between gardeners and non-gardeners is partly due to methodological limitations of existing studies including the use of cross-sectional designs, convenience samples, small sample sizes, and selfreported measurements of health outcomes [10, 21]. Alaimo et al. particularly encouraged the next generation of gardens' research to take advantage of so called "natural experiments" (i.e. interventional researches in which the experimental conditions are self-determined without being manipulated by researchers) to evaluate the health impacts of community gardens [10]. While several randomized controlled trials on home or community gardening are under way in the United States [22-25], natural experiments offer another opportunity of longitudinally assessing the changes induced by community gardening [26].

Beyond health-related outcomes, shaping behavioral patterns from a sustainability perspective could lead to more sustainable lifestyles [27]. Community gardening, for example, could raise gardeners' environmental awareness and encourage the adoption of more sustainable dietary practices by fostering collective thinking about biodiversity and eco-friendly practices [28]. Additionally, by providing access to fresh food harvested from the garden, community gardens could favor food affordability by reducing food expenses [29] or changing purchasing behaviors [30]. Community-based interventions targeting gardening thus appear as a relevant tool to positively influence the three fundamental pillars of sustainability - namely social (including health outcomes), environment and economy [31] and therefore, promote more sustainable lifestyles. The term "lifestyles" is commonly used in public health to define a cluster of habits that include an individual's behaviors, inclinations, preferences and values that affect health status [32]. The present study was aimed at assessing the impact of urban community garden participation on the adoption of more sustainable lifestyles on free-living adults in a European context. We used both qualitative and quantitative approaches to better explore changes that may have occurred in gardeners' lives during the first year of gardening, and the potential benefits to their physical, social and mental health.

\section{Methods}

\section{Study setting, population and design}

JArDinS is a quasi-experimental study conducted between 2018 and 2019. The design and protocol of the study have already been described in a previous paper [33]. A convenience sample of new community gardeners (herein referred to as "gardeners") was established in 2018 (experiment group). All known community gardens $(n=34)$ in 
Montpellier (France) were contacted and informed about the study. Garden plots were grown either collectively or individually ( $\leq 20 \mathrm{~m}^{2}$ for individual plots). Gardens with collective plots were accessible to anyone who joined the garden organization and paid the annual dues. For gardens with individual plots, gardeners usually registered on a waiting list. Throughout the gardening season (from March to November), each new individual entering one of the contacted gardens was invited to participate in the JArDinS study. Inclusion criteria were as follows: 1) starting gardening in a community garden, 2) being willing to be involved in the study for 1 year, 3) be at least 18 years old, 4) being able to read French, and 5) residing in the city of Montpellier. Exclusion criteria were: 1) past experience of at least one household member in community gardening, 2) selfreported extensive experience in gardening, 3) never shopping for household food supply, and 4) having a chronic disease. In parallel, a matched-control group of non-gardeners was formed by selecting volunteers participating in a population-based survey on food supply behaviours in Montpellier ("Mont'Panier" survey). To be selected, participants from the control group must neither garden, nor have had prior experience in a community garden or have planned to join one. Matching criteria were: age $(<30$; 30 50; > 50 years old), gender, household income $(<1110$; 1110-1999; 2000-2699; $\geq 2700 €$ per month and per consumption unit) and household composition (single adult with no child; single adult with at least 1 child; $>1$ adult with no child; $>1$ adult with at least 1 child). Data were collected at baseline (t0) and 12 months later (t1). Household fruit and vegetables supply was the main outcome of the study. A total sample size of 160 participants (80 gardeners and 80 non gardeners) was previously evaluated to detect an increase of one portion of fruit and vegetables per day and per person in the gardeners group with $80 \%$ power at the 0.05 level of significance and a planned attrition rate of $30 \%$ [33].

The study was conducted in accordance with the Declaration of Helsinki, and the protocol was approved by the Ethics Committee of the French Institute for Health and Medical Research and the Commission Nationale Informatique et Libertés (IRB00003888); verbal informed consent was obtained following recommendation of the Research Ethics Committee. The JArDinS study was registered at clinicaltrials.gov as NCT03694782. Participants received a $15 €$ voucher at to and at $\mathrm{t} 1$ for returning all data collection materials duly completed.

\section{Quantitative evaluation}

\section{Data collection and lifestyles sustainability assessment}

Details about collection and assessment of all outcome variables of the JArDinS study have been summarized in a previous methodological paper [33]. To investigate the social/health, environmental and economic dimensions of sustainability, we instructed participants to 1) complete a 1-month food supply diary and collect food receipts, 2) wear a hip-worn triaxial accelerometer (wGT3X-BT or wActiSleep-BT, Actigraph, Pensacola, FL, USA) for 9 consecutive days and 3) fill in an online questionnaire including self-reported body height and weight, and validated questionnaires on mental wellbeing, social health, sensitivity to food waste and connection with nature.

The social/health dimension was approached by measuring: 1) the healthiness of household's food supply based on $i$ ) fruit and vegetables household supply (including fruit and vegetables from the garden) in gram consumed per day and per person living in the household and being concerned by the food supplies (see Additional file 1); ii) two indicators of nutritional quality: the mean adequacy ratio (MAR) which assesses the percentage of adequacy in relation to 20 essential nutrients [34], and the mean excess ratio (MER), which assesses the excess intake of sodium, free sugars and saturated fatty acids [35]; iii) the Healthy Purchase Index (HPI) estimating the healthiness of household food purchases, based on food expenditure only [36]; 2) participant's physical activity energy expenditure (PAEE) and time spent during daytime in inactivity $(<1.5$ METs), light intensity activities (between 1.5 and 3 METs) and moderate-to-very vigorous intensity activities (>3 METs) using a previously validated model that combines an automatic activity-recognition algorithm with an activity-specific count-based model [37]; 3) selfreported BMI; 4) mental well-being (WEMWBS) [38]; and 5) level of social isolation (UCLA Loneliness Scale, V3) [39]. Additional file 1 further describes specific details regarding the data analyses of food supply diary and accelerometer.

The environmental lifestyles dimension was assessed through key indicators of food practice sustainability, namely 1) the greenhouse gas emissions (GHGE, in $g$ $\mathrm{CO}_{2} \mathrm{eq}$ ), atmospheric acidification (in $\mathrm{g} \mathrm{SO}_{2} \mathrm{eq}$ ), marine eutrophication (in $\mathrm{g} \mathrm{Neq}$ ) and contribution of animal proteins to total proteins of household food supply; 2) participants' sensitivity to food waste (Sensitivity to food waste scale) [40]; 3) and their connection with nature (Nature Relatedness Scale) [41]. Because of the skewed distribution of the sensitivity to food waste score participants were classified in two categories: "high sensitivity to food waste" (score $\geq$ median at $\mathrm{t} 0$ ) or "low sensitivity food waste" (score $<$ median at $\mathrm{t}$ ) ).

The economic dimension was approached by household food expenditure and expenditure share by food groups. For food coming from the garden, or from gifts or food aid, a theoretical expenditure was attributed based on the mean observed food price for that product in the rest of the sample. 


\section{Additional information}

The online questionnaire (see Additional file 2) further provided information on socioeconomic characteristic of participants, percentage of meals consumed outside of the home in total household meals, participant's exclusion of selected foods and perceived competence in gardening ("beginner", "intermediate", "advanced"), as well as a social desirability scale (the Balanced Inventory of Desirable Responding Short Form) [42]. The questionnaire for gardeners also contained a specific section on the community garden to collect information on the characteristics of the garden, garden-to-home distance and transportation used to go to the garden at t0; and periods of inactivity in the garden during the past year (ranging from none to $>9$ months), as well as frequency of gardening during activity periods (" $\geq 1$ time/week", "1-3 times/month", "< 1 time/month") at $\mathrm{t} 1$.

To compare our results to gardeners' perception of changes that took place in their lives, we sent them an online post-survey questionnaire, in which gardeners were asked if they had perceived a change in their fruit and vegetable consumption, physical activity, life satisfaction and social relation during the past year (five response categories: "strong increase", "slight increase", "no change", "slight decrease" or "strong decrease") and if that change was due to the community garden (Additional file 2).

\section{Statistical analyses}

Sociodemographic characteristics and key outcome variables of participants at baseline were compared between the two groups (gardeners vs non-gardeners) using paired t-test for continuous variables and McNemar test for categorical variables. The changes in the lifestyles sustainability components between the two groups across time (pre- to post-test) was investigated only for remaining gardener-control pairs at $\mathrm{t} 1$. We used linear mixed-effect models (SAS PROC MIXED) for continuous variables and logistic mixed-effect models (SAS PROC GLIMMIX) for dichotomous variables. Group, time and the time"group interaction were treated as a fixed effect. We modelled within-person variation by using a compound symmetry covariance matrix. Significant time*group interaction indicated a difference in outcome over time between the two groups. Different adjustments were used depending on the outcome variable. Models on physical activity were adjusted for baseline education level and BMI (Model A). Models on food supply and models on self-report data were further adjusted for percentage of meals consumed outside of the home (Model B), and social desirability scale (Model C), respectively. Model on BMI was adjusted for baseline education level, percentage of meals consumed outside of the home and social desirability scale (Model D).
Indicators with skewed distribution were logtransformed to improve heteroscedasticity and improve normality of the residuals. Post-hoc analyses were performed only on active gardeners (who visited the garden at least once a month throughout the year) and on those who did not drop out the garden during the year.

We performed all analyses with the SAS statistical software package Ver. 9.4 for Windows (SAS Institute, Cary, NC, USA), with statistical significance at $p<0.05$.

\section{Qualitative evaluation}

The qualitative evaluation was based on interviews with 15 community gardeners in the study conducted over 7 weeks in May and June 2019. We selected a sample size of 15 as it allowed us to select individuals from geographically and socioeconomically varied community gardens. The interview sample included 11 females and 4 males. All interviews were conducted and recorded in French and later professionally transcribed into English for analysis using an online translation and transcription service. We held interviews in the participants' homes or community gardens, whichever was more convenient. Interviews ranged from 11 to $50 \mathrm{~min}$. Using a semi-structured interview guide, we led interviews with 5 to 7 open-ended questions directed at the new gardener experience to better understand changes that may have occurred in gardeners' lives during the first year of community garden participation. We checked each transcript carefully for accuracy against the recordings after receiving it from the transcription service. Assisted by ATLAS.ti qualitative software, we followed grounded theory methodology by analysing the data inductively without a predetermined codebook [43]. We selected key concepts by extracting repetitive topics in the data for closer analysis, sorting codes into larger code groups, and visually networking these groups to distil salient themes [44].

\section{Results \\ Participant eligibility and sample size}

In total 296 potential participants were approached between March and November 2018 (152 gardeners starting gardening in a community garden and 144 matched non-gardeners). Fifty-nine were excluded, as they did not meet the inclusion criteria and 85 declined to participate or did not answer resulting in a final sample of 155 participants at baseline (response rate: $61.0 \%$ for gardeners and $70.2 \%$ for controls) (Fig. 1). Only 14 participants were lost to follow-up between $\mathrm{t} 0$ and $\mathrm{t} 1$ (conducted from March to November 2019), leading to 66 remaining matched pairs for the analysis. Gardeners came from 19 different community gardens and held either a collective $(68.2 \%)$ or 


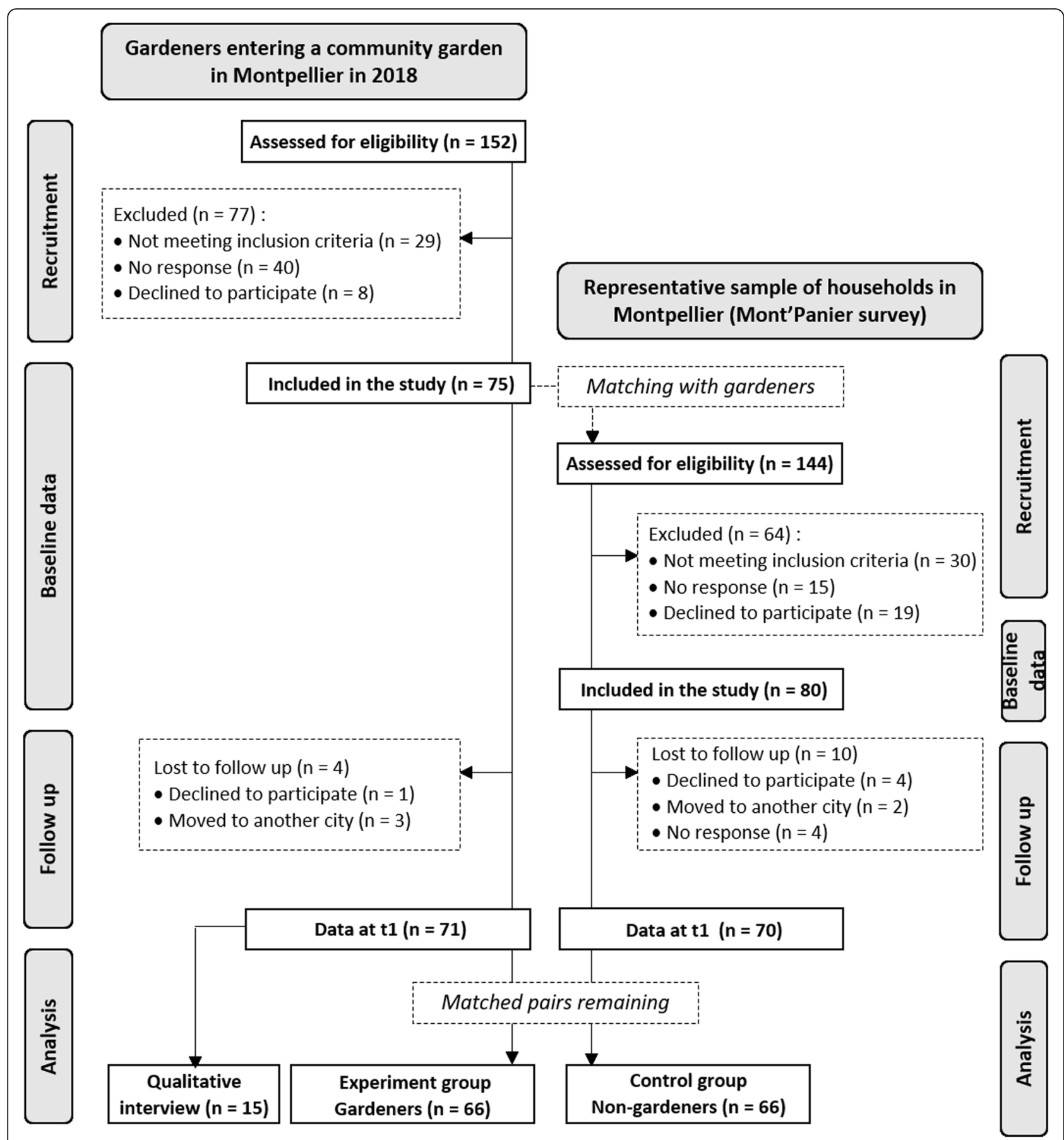

Fig. 1 Flow diagram of the JArDinS study

individual (31.8\%) plot. We saw no difference with mixed models on gardeners using garden type as fixed effect (collective versus individual plots), therefore the data on garden type were pooled together. Garden-to-household distance varied between gardeners: $72,7 \%$ walked or biked to the garden (mean travel time: $8.6 \mathrm{~min}$ ) and $27.3 \%$ used car or public transportation (mean travel time: $21.2 \mathrm{~min}$ ).

\section{Participant characteristics}

Sociodemographic characteristics of the participants at baseline are shown in Table 1 . The mean age of gardeners was 44.0 years. Most of them were females, held a university degree and reported having no past experience in gardening. There were some differences between the gardeners and the controls at baseline: 
Table 1 Baseline sociodemographic characteristics of gardeners and non-gardeners of the JArDinS study

\begin{tabular}{|c|c|c|c|}
\hline & Gardeners $(n=66)$ & Non-gardeners $(n=66)$ & $P$-value ${ }^{a}$ \\
\hline \multicolumn{4}{|l|}{ Matching criteria } \\
\hline \multicolumn{4}{|l|}{ Individual level } \\
\hline Age (year), mean (SD): & $44.0(14.0)$ & $44.9(13.7)$ & 0.706 \\
\hline Females, n (\%) & $50(75.8)$ & $50(75.8)$ & 0.808 \\
\hline \multicolumn{4}{|l|}{ Household level } \\
\hline Household structure, n (\%): & & & 0.999 \\
\hline Single adult with no child & $25(37.9)$ & $25(37.9)$ & \\
\hline Single adult with at least 1 child & $6(9.1)$ & $7(10.6)$ & \\
\hline$>1$ adult with no child & $20(30.3)$ & $20(30.3)$ & \\
\hline$>1$ adult with at least 1 child & $15(22.7)$ & $14(21.2)$ & \\
\hline Household income ( $€ /$ month/consumption unit), n (\%): & & & 0.605 \\
\hline$<1110$ & $14(21.2)$ & $11(16.7)$ & \\
\hline 1110-1999 & $29(43.9)$ & $26(39.4)$ & \\
\hline $2000-2699$ & $11(16.7)$ & $17(25.8)$ & \\
\hline$\geq 2700$ & $10(15.2)$ & $9(13.6)$ & \\
\hline NA & $2(3.0)$ & $3(4.5)$ & \\
\hline \multicolumn{4}{|l|}{ Other sociodemographic characteristics } \\
\hline \multicolumn{4}{|l|}{ Individual level } \\
\hline \multicolumn{4}{|l|}{ Education level, n (\%): } \\
\hline Elementary school & $1(1.5)$ & $1(1.5)$ & $0.049^{b}$ \\
\hline Secondary school & $15(22.7)$ & $6(9.1)$ & \\
\hline University or equivalent & $50(75.8)$ & $59(89.4)$ & \\
\hline $\mathrm{BMI}\left(\mathrm{kg} / \mathrm{m}^{2}\right)$ & $22.6(3.0)$ & $23.8(4.0)$ & 0.046 \\
\hline No meat or fish eater, n (\%) & $13(19.7)$ & $8(12.1)$ & 0.157 \\
\hline Experience in gardening, $\mathrm{n}(\%)$ : & & & $1.000^{\mathrm{c}}$ \\
\hline Beginner & $47(71.2)$ & $47(71.2)$ & \\
\hline Intermediate & $19(28.8)$ & $17(25.8)$ & \\
\hline Advanced & 0 & $2(3.0)$ & \\
\hline \multicolumn{4}{|l|}{ Household level } \\
\hline $\begin{array}{l}\text { Percentage of meals consumed outside of the home in } \\
\text { total household meals (\%), mean (SD) }\end{array}$ & $16.4(11.7)$ & $20.6(15.3)$ & 0.033 \\
\hline
\end{tabular}

a $P$-value for the difference between the two groups using paired t-test for age and BMI, and McNemar test for other variables

b The first two categories were grouped together for statistical analysis

c The last two categories were grouped together for statistical analysis

gardeners had lower education level, lower BMI and gardeners' households reported lower percentages of meals consumed outside of the home.

\section{Change in sustainability of lifestyles}

Results of the mixed-effect models are shown in Table 2. At baseline, there were no pre-existing differences between the two groups on any of the components of lifestyles except for the contribution of added fats \& seasonings to total household food expenditure. For both groups, physical activity significantly decreased between to and $\mathrm{t} 1$, while inactivity increased. Other changes due to time were, in both groups, an increase of BMI, an increase of sensitivity to food waste and a decrease in beverages expenditure share. At $\mathrm{t} 1$, more than half of gardeners $(n=38)$ had not retrieved any fruit or vegetables from the garden and for the others the mean quantity harvested fruit or vegetables was 33.7 (SD 40.7) $\mathrm{g} / \mathrm{d}$ per person [median: 17.1, IQR: 3.6-49.9] (data not shown).

No significant impact of participating in a community garden was observed on the main outcome variable (household fruit and vegetables supply) or on any of the other outcomes, as shown by the lack of significance for the interaction term (group"time) (Table 2). Even when removing the theoretical expenditure attributed to produce from the garden, there was no measurable impact 
Table 2 Group differences and time effect of components of lifestyles sustainability among gardeners and non-gardeners ${ }^{\mathrm{a}}$

\begin{tabular}{|c|c|c|c|c|c|c|c|c|}
\hline \multirow[t]{2}{*}{ Sustainability components, means (SD) ${ }^{\mathbf{b}}$} & \multirow[t]{2}{*}{ Model $^{\mathrm{c}}$} & \multicolumn{2}{|c|}{ Gardeners $(n=66)$} & \multicolumn{2}{|c|}{$\begin{array}{l}\text { Non-gardeners } \\
(n=66)\end{array}$} & \multirow[t]{2}{*}{$\begin{array}{l}\text { Group } P- \\
\text { value }\end{array}$} & \multirow[t]{2}{*}{$\begin{array}{l}\text { Time } P \text { - } \\
\text { value }\end{array}$} & \multirow[t]{2}{*}{$\begin{array}{l}\text { Group* } \\
\text { Time } P \text {-value }\end{array}$} \\
\hline & & to & t1 & to & t1 & & & \\
\hline \multicolumn{9}{|l|}{ Social/Health dimension } \\
\hline \multicolumn{9}{|l|}{ Healthiness of household's food supply ${ }^{\mathrm{d}, e}$} \\
\hline Fruit \& Vegetables ${ }^{f}(\mathrm{~g} / \mathrm{d} / \mathrm{p})$ & B & $\begin{array}{l}402.4 \\
(238.2)\end{array}$ & $\begin{array}{l}400.0 \\
(231.2)\end{array}$ & $\begin{array}{l}433.6 \\
(285.4)\end{array}$ & $\begin{array}{l}445.6 \\
(304.5)\end{array}$ & 0.241 & 0.637 & 0.999 \\
\hline MAR (\% adequacy/2000 kcal) & B & $76.5(7.3)$ & $75.8(8.1)$ & $76.3(7.1)$ & $76.9(6.5)$ & 0.679 & 0.936 & 0.356 \\
\hline MER (\% excess/2000 kcal) & B & $96.6(19.5)$ & $96.1(23.4)$ & $100.2(25.3)$ & $98.8(29.7)$ & 0.617 & 0.705 & 0.844 \\
\hline HPI [range: 0-15] & B & $8.7(2.1)$ & $9.0(2.1)$ & $9.0(2.3)$ & $9.1(1.9)$ & 0.218 & 0.282 & 0.604 \\
\hline \multicolumn{9}{|l|}{ Physical activity ${ }^{9}$} \\
\hline PAEE (kJ/kg/d) & A & $43.2(13.8)$ & $40.3(12.3)$ & $41.9(12.4)$ & $39.9(13.5)$ & 0.489 & 0.027 & 0.664 \\
\hline Inactivity (h/d) & A & $9.4(1.4)$ & $9.9(1.5)$ & $9.4(1.5)$ & $9.8(1.4)$ & 0.333 & $<0.0001$ & 0.995 \\
\hline Low-intensity activity (h/d) & A & $2.8(0.8)$ & $2.7(0.9)$ & $2.8(1.0)$ & $2.6(0.8)$ & 0.792 & 0.003 & 0.544 \\
\hline $\begin{array}{l}\text { Moderate-to-vigorous intensity activity } \\
\text { (h/d) }\end{array}$ & A & $1.9(0.9)$ & $1.6(0.7)$ & $1.8(0.7)$ & $1.7(0.8)$ & 0.555 & $<0.001$ & 0.362 \\
\hline $\mathrm{BMI}\left(\mathrm{kg} / \mathrm{m}^{2}\right)$ & D & $22.6(3.1)$ & $22.8(3.1)$ & $23.8(4.0)$ & $23.9(4.1)$ & 0.111 & 0.038 & 0.679 \\
\hline WEMWBS [range: 14-70] & C & $51.1(6.7)$ & $51.5(6.9)$ & $51.8(6.7)$ & $51.5(5.7)$ & 0.406 & 0.899 & 0.546 \\
\hline UCLA Loneliness Scale [range: 20-80] & C & $42.1(10.4)$ & $40.1(10.9)$ & $40.1(9.8)$ & $40.5(9.5)$ & 0.727 & 0.570 & 0.227 \\
\hline \multicolumn{9}{|l|}{ Environmental dimension } \\
\hline High sensitivity to food waste, $\mathrm{n}(\%)$ & C & $30(45.5)$ & $40(60.6)$ & $27(40.9)$ & $30(45.5)$ & 0.274 & 0.018 & 0.214 \\
\hline Nature Relatedness Scale [range: 1-5] & C & $4.1(0.5)$ & $4.1(0.5)$ & $3.9(0.5)$ & $4.0(0.5)$ & 0.060 & 0.198 & 0.395 \\
\hline \multicolumn{9}{|l|}{$\begin{array}{l}\text { Environmental impact of household's food } \\
\text { supply d,e }\end{array}$} \\
\hline GHGE (in $\left.\mathrm{g} \mathrm{CO}_{2} \mathrm{eq} / 2000 \mathrm{kcal}\right)^{\mathrm{f}}$ & B & $3099(997)$ & $3151(1131)$ & $3294(886)$ & $3240(889)$ & 0.382 & 0.836 & 0.678 \\
\hline $\begin{array}{l}\text { Atmospheric acidification } \\
{\text { (in } \mathrm{SO}_{2} \text { eq/2000 kcal) }}^{f}\end{array}$ & B & $33.1(12.2)$ & $33.3(12.0)$ & $37.6(15.0)$ & $35.4(12.1)$ & 0.256 & 0.398 & 0.373 \\
\hline $\begin{array}{l}\text { Marine eutrophication (in g Neq/2000 } \\
\text { kcal) }^{f}\end{array}$ & B & $11.9(3)$ & $12.5(3.9)$ & $13.3(3.5)$ & $13(3.9)$ & 0.124 & 0.972 & 0.271 \\
\hline Animal proteins (in \% of total proteins) & B & $56.9(16.1)$ & $56.4(17.4)$ & $61.8(15.4)$ & $59.1(15.6)$ & 0.368 & 0.091 & 0.245 \\
\hline \multicolumn{9}{|l|}{ Economic dimension } \\
\hline Household food expenditure $(€ / d / p)^{d, e}$ & B & $7.0(3.1)$ & $6.7(3.2)$ & $6.8(3.3)$ & $6.8(3.2)$ & 0.841 & 0.682 & 0.630 \\
\hline \multicolumn{9}{|l|}{ Expenditure share by food groups (\%) $)^{\mathrm{d}, \mathrm{e}}$} \\
\hline Fruits \& Vegetables & B & $26.5(11.1)$ & $27.0(10.4)$ & $26.6(12.3)$ & $29.4(15.6)$ & 0.258 & 0.100 & 0.237 \\
\hline Starches & B & $10.1(5.2)$ & $10.6(5.1)$ & $9.2(4.7)$ & $8.8(4.5)$ & 0.177 & 0.836 & 0.228 \\
\hline Meat, fish \& Eggs & B & $18.8(9.5)$ & $18.7(10.2)$ & $20.2(9.2)$ & $20.2(10.9)$ & 0.507 & 0.908 & 0.901 \\
\hline Dairy products & B & $11.8(5.1)$ & $11.5(4.8)$ & $11.3(4.4)$ & $11.2(5.2)$ & 0.495 & 0.669 & 0.825 \\
\hline Mixed dishes ${ }^{f}$ & B & $8.9(6.2)$ & $8.4(6.1)$ & $8.3(6.1)$ & $8.9(8.2)$ & 0.098 & 0.496 & 0.998 \\
\hline Sweet products & B & $10.4(5.5)$ & $11.7(8.2)$ & $11.1(5.6)$ & $10.1(6.0)$ & 0.853 & 0.855 & 0.078 \\
\hline Added fats \& seasonings ${ }^{f}$ & B & $4.4(3.0)$ & $4.9(2.8)$ & $3.5(2.6)$ & $3.6(2.6)$ & 0.003 & 0.507 & 0.216 \\
\hline Beverages $^{f}$ & B & $9.5(6.2)$ & $8.4(5.8)$ & $10.1(7.4)$ & $8.1(6.1)$ & 0.745 & 0.021 & 0.240 \\
\hline
\end{tabular}

${ }^{a}$ Abbreviations: GHGE GreenHouse Gas Emissions, HPI Healthy Purchase Index, MAR Mean Adequacy ratio, MER Mean Excess Ratio, PAEE Physical activity energy expenditure, WEMBWS The Warwick-Edinburgh Mental Wellbeing Scale

${ }^{b}$ Unless specified

c Model $\mathrm{A}$ was adjusted on BMI and education level. Model $\mathrm{B}=$ Model $\mathrm{A}+$ percentage of meals consumed outside of the home. Model $\mathrm{C}=$ Model $\mathrm{A}+$ social desirability scale. Model D was adjusted on education level, percentage of meals consumed outside of the home and social desirability scale

dVariable measured at the household level and not at the individual one

${ }^{\mathrm{e}}$ Including produce from the garden and foods from gifts or food aid. For food expenditure variables, a mean price was attributed to these foods (see Method section)

${ }^{f}$ Variable was log-transformed to improve normality

${ }^{9}$ Participants with less than 3 valid days ( $\geq 10 \mathrm{~h}$ of wearing the accelerometer wearing during daytime) were excluded from the analysis resulting in 65 gardeners and 65 controls at t0, and 64 gardeners and 62 controls at $t 1$ 
of garden participation on total food expenditure and on food-group expenditure shares (data not shown).

At $\mathrm{t} 1,24 \%$ of the gardeners surveyed had dropped out the garden during the year. There was inter-individual variability in the frequency of garden attendance during the year, the majority of gardeners visiting the garden at least once a month throughout the year $(56.1 \%)$ or over a period from 6 to 9 months (18.2\%), while others visited the garden for shorter periods, from 3 to 6 months $(16.6 \%)$ or only few times a year $(9.1 \%)$. Post-hoc analyses also showed a non-significant effect of participating in a community garden on outcome variables on subsamples including active gardeners only $(n=37)$ or those who did not drop out the garden during the year $(n=$ 50) (Additional files 3 and 4). In the post-survey questionnaire, the majority of gardeners stated they did not perceive any change in their fruit and vegetable consumption, physical activity, life satisfaction and social relation due to gardening (Fig. 2).

\section{Qualitative evaluation}

The qualitative evaluation provided some plausible explanations for the lack of change in gardeners' lifestyles observed in the quantitative study. Of the 15 gardeners interviewed, 9 were active gardeners, 4 visited the garden over a period from 6 to 9 months and 2 less than 3 months.

Nine respondents perceived no change in their lifestyles after 1 year of gardening. This lack of perceived benefit cannot only be explained by having a negative gardening experience, as one gardener described: "My life is the same as before [the garden], but it's true that it's a plus to have this garden anyway. It's one of the positive things in my life, but after that it's not really changing my life actually" (Female 1, age 54). A couple of respondents pointed out that participation in the garden was just part of their health and environmental consciousness: "I was already a nature enthusiast. What I mean is, that I have always been environmentally conscious, and caring about nature" (Male 1, age 34). It is also possible that a follow-up period of 1 year was not sufficient to perceive changes. For example, one woman shared: "I hope I'll improve over time" (Female 6, age 63).

The interview also highlighted several barriers to community garden participation, the most frequently mentioned being the lack of time to garden. Nine gardeners, mostly females, confessed facing greater challenges balancing the demands of gardening with their personal and professional lives, which could lead to feelings of guilt. One gardener mentioned:

At first, I didn't know if I would have enough time to invest in the garden [...]. Indeed, it actually requires a lot of time. [...] You see what time I get home from work and everything. I don't have time for this. I see them working. At first, I felt guilty, I thought, "Oh, now I see them and so on, and then I don't go there"

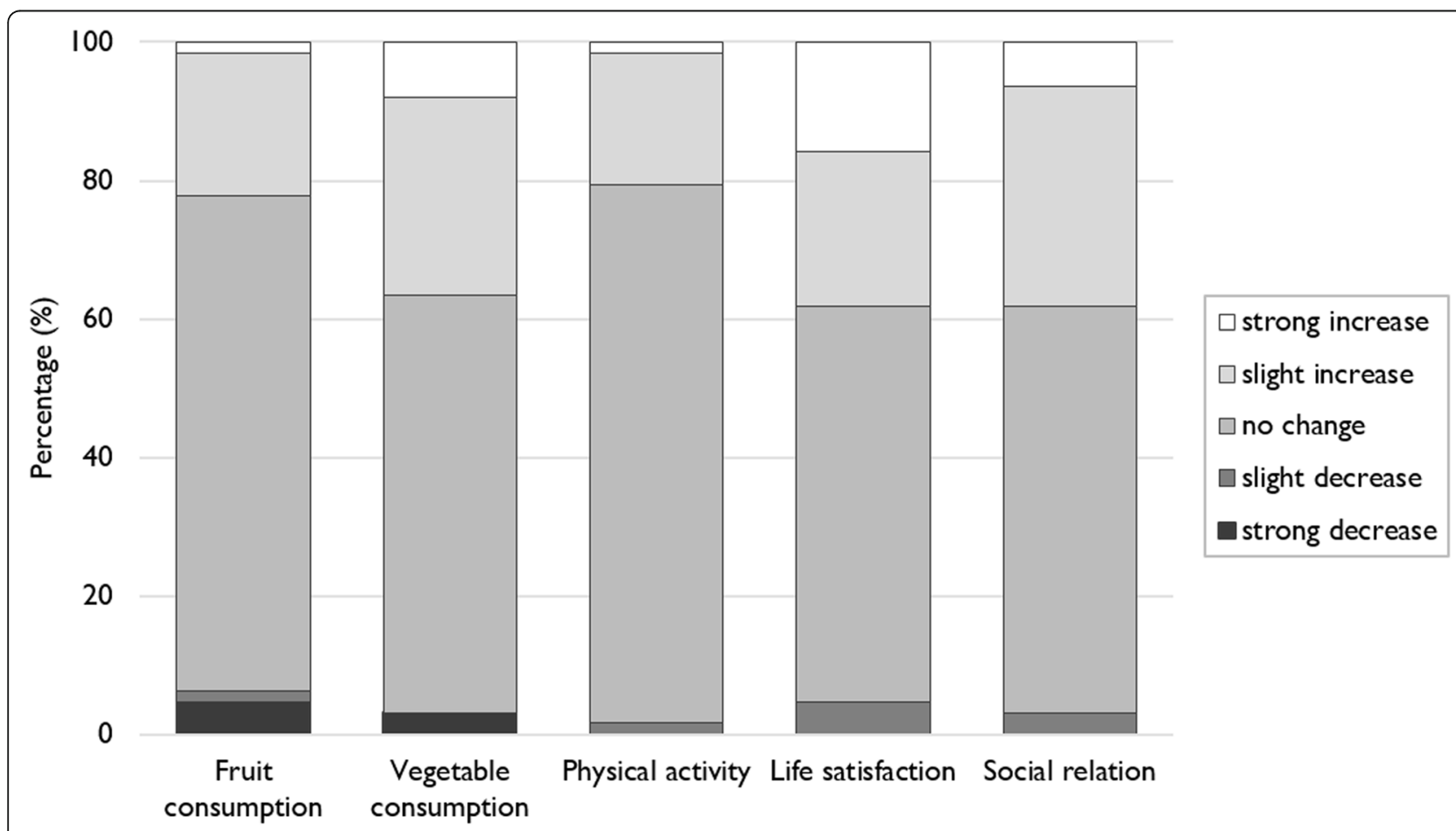

Fig. 2 Perceived change by gardeners in fruit consumption, vegetable consumption, physical activity, life satisfaction and social relation after the first year in a community garden $(n=63)$ 
I had no experience of gardening and how long it took. [...] It's true that it's great, it's almost in a meditative state, it brings me a lot of well-being, but it takes a lot of time (Female 3, age 42).

The demands of daily life are an important factor associated with participation, regardless of gardeners' motivation:

I struggle to go there regularly. I said yes, I signed up, and I thought I was going to participate a lot. In the end, not that much, because I had a lot of things happen. My place of work changed. My husband was very ill. My father was very ill, while he's in Toulouse, etc. My car is broken, there are things like that... [...] If it was in the same neighbourhood it would be easier. (Female 8, age 61).

The distance between the garden and the house can be an additional source of discouragement outweighing benefits from the garden:

What's difficult is not the time, it is the trip. It's hard to organize because you don't come for 10 minutes, you come to stay longer than that. Therefore, the travel time, and the round trips make it challenging to always find the time to do it. If it was just next door, it would have been easier. (Female 4, age 41).

These quotations underline how difficult it was for participants to make time in their busy lives to access the garden away from their homes. Other barriers mentioned by the gardeners were difficulties of gardening and the lack of experience $(n=3)$. One gardener explained that:

What I first noticed was that this work is not actually simple as people think. It's not just planting and harvesting. You have to know what you're planting. You have to know many plants. I know some of them. No, it's not an easy job. You need to also know how to conserve water because you can garden by using lot of water especially here in the South. It's a bit risky. It's depends. Since we don't want to use pesticides, we want it to be as natural as possible. It's not always an easy job. (Female 7, age 65).

Lack of gardening knowledge, especially for beginning gardeners, can lead to a negative gardening experience if they are not helped or supervised by other more expert gardeners, as explained by this woman:

I had to make mistakes, I don't know which ones because we don't have-- It's a garden where there aren't many people, so it's hard to get advice, it's hard to look at on the internet. That's not what I expect from a garden, it's the discussion, that's what I want to get tips, because there are people who have been doing this for a longer time. It didn't work for me. (Female 2, age 60).

The difficulty of gardening, especially soil preparation and bending down can be a hindrance for people with fragile health such as the elderly: "After all, I'm 63 years old, and I don't have the strength, the physical resistance to mix the soil. Moreover, I sleep very badly because I feel pain everywhere. (Female 6, age 63).

Although many gardeners mention the friendly moments in the garden, tension related to the management of garden can arise and lead to conflicts between gardeners. This was notably the case for one of the interviewed gardeners:

I refuse all fixed patterns of thinking. These people, unfortunately, behind their participatory democracy side, are oligarchs, sorry. I can't stand the oligarchy. Oligarchy is the power of a few behind a pseudodemocratic form. I don't want to be given orders, at least not in the garden, so I refuse to see them and leave. (Female 10, age 48).

\section{Discussion}

JArDinS is the first longitudinal study to examine the causal effect on gardeners' lifestyles of participating in a community garden, 1 year after entry. We found no impact of one-year garden participation on healthiness of household's food supply, physical activity, BMI, mental well-being and social health, connection to nature, sensibility to food waste, as well as, environmental impact and expenditure of food supply. The present results are not in line with previous studies that concluded on the health, social, environmental and economic benefits of community gardening [11-13, 15-17, 19, 20, 30]. The JArDinS study was specifically implemented to overcome shortcomings from the existing literature. Our results suggest that previous cross-sectional studies have been subject to selection bias. Indeed, it is likely those studies have been conducted on a small percentage of highly motivated and experienced gardeners who did not abandon the activity because they already had positive health consciousness and/or environmental attitudes. Additionally, previous studies were conducted predominantly amongst vulnerable populations such as socioeconomically disadvantaged neighborhoods or ethnic minorities in U.S. cities $[45,46]$, and therefore outcomes cannot easily be generalized to other settings and other populations. Lastly, in previous studies, health outcomes were mostly collected by declarative questionnaires, which are subject to desirability and memory bias [47]. In particular, frequency of fruit and vegetable intake was mainly 
estimated based on short food frequency questionnaire [11-15], which validity is moderate [48]. The measure of household food and beverage purchasing behaviour through the collection of food receipts and records offer a more objective approach to estimate dietary behaviours at the household level [49]. Similarly, self-reported physical activity is less accurate than objective methods for estimating PAEE and PA intensity [50]. Among the objective measurement tools, accelerometers allow to capture large amounts of data over several days and have gained popularity to quantify more precisely PAEE and PA intensity [51].

Our results suggest that practicing gardening for 1 year in a community garden may not be sufficient to modify health and sustainability behaviors in a French setting. The observed low gardener involvement might explain the lack of effect of community gardening on gardeners' lifestyles. However, post-hoc analysis on active gardeners only did not show a positive effect of gardening on gardeners' lifestyles, but these findings are to be taken with caution because the reduction of the sample also reduces statistical power. Furthermore, it can also be argued that even the most active gardeners did not visit the garden enough to result in a lifestyle change. In the litterature, strong evidence of the health benefits of gardening mainly comes from gardening programs in school or medical settings where the activity is supervised and carried out regularly, usually on a weekly basis [3, 52, 53]. Additionally, in these institutionalized settings the gardening activity is often accompanied by other actions such as, in school, nutrition education courses, cooking classes, introduction of healthy foods in the school lunchrooms [3]. Hence, multicomponent programs are more likely to modify health outcomes [3]. More broadly, many questions regarding the health benefits of exposure to green spaces remain unanswered and further studies are needed to understand which forms of nature contact are the most beneficial, the duration of exposure needed, the variation of effects across populations and settings as well as the psychological pathways involved [54].

Interviews showed that lack of time and knowledge about gardening, health problems or conflicts with other gardeners contributed to gardener discouragement. While motivations for participating in community gardens are well documented in the literature, there are few studies that focus on the barriers encountered by gardeners and they all agree that lack of time, knowledge, practical skills, physical capacity or conflicting personal and social expectations are major hindrances to gardener involvement [55-59]. These obstacles can be expected to be particularly difficult for beginner gardeners; thus preventing them from changing their behaviour. Additionally, it is likely that French gardeners entered the gardens with a higher quality diet and more physical activity compared to gardeners in lowincome areas of the U.S. more inclined to suffer from inequalities in access to healthy food and recreational facilities $[60,61]$. The hypothesis of a pre-established health consciousness of gardeners before entering the garden was supported by the qualitative evaluation. Some gardeners also expressed pre-existing environmental awareness. We found that, compared to non-gardeners, only active gardeners had a slightly but significantly higher connection to nature at baseline. While there was no difference between less active gardeners and non-gardeners, this significant trend reinforces the idea that the most involved gardeners might have been more predisposed to stay in the garden because of positive attitudes enabling them to better cope with the difficulties of gardening.

Given that community garden participation is particularly likely to enhance health and wellbeing of vulnerable populations [46], one can assume that the recruitment of less educated, low-income gardeners would have led to different conclusions. Nevertheless, a survey conducted in Toronto revealed that food-insecure households considered gardening programs unsuited to their busy schedules, interests, or needs and preferred to use food banks instead $[58,62]$. An ongoing trial using rigorous assessment methods ( $24 \mathrm{~h}$ recall and accelerometer) in Denver (USA) will provide further insight regarding the causal relationship between community gardening and health in a mixed-income population in a nonEuropean setting [23].

Surprisingly, we found an increase in inactivity and BMI after 1 year in both groups. It is likely that agerelated weight gain explained the BMI increase. Participants gained on average $0.4 \mathrm{~kg}$ in the year, which is similar to weight change observed in three U.S. cohorts [63]. Regarding inactivity, participants were used to the Actigraph at $\mathrm{t} 1$ and probably forgot that they were wearing it, resulting in a decrease of the desire to emphasize their "healthy behavior".

We acknowledge that our study is not without limitations. First, the non-random design conveys an important risk of bias [64]. One major threat of is the risk of non-comparability between groups [65]. At baseline gardeners had slightly lower level of education, lower BMI and their households consumed less meals outside of the home, which is consistent with their higher expenditure for added fats \& seasonings (i.e. cooking ingredients) than non-gardeners. Random sampling was not achievable in our setting because new membership and plot renewal in community gardens are under the control of local authorities or private managers. Nevertheless, longitudinal pre-post quasi-experimental designs offer robust alternative to randomized control trials to determine a causal relationship [66]. In addition, we used a pairwise matching process controlling for individual- 
level and contextual-level variables to reduce selection bias and strengthen internal validity of the study [66]. Furthermore natural experiments improve external validity by giving a more realistic representation of the effectiveness of an intervention in a real world setting [66]. Second, despite investigating several components of lifestyles across the three dimensions of sustainability, it is always possible that other unmeasured variables might have changed following gardening participation. Third, the diversity of the data collection tools and the longitudinal follow-up required a significant involvement of the participants which could have led to the recruitment of people more concerned about their health than the general population, and therefore underestimate the effect of the intervention [67]. In our case, the majority of participants held a university degree and displayed healthier dietary patterns at baseline than the French general population [68], with a higher intake of fruits, vegetables and nuts (398 vs $264 \mathrm{~g} / \mathrm{d}$ per person) (data not shown). Fourth, it can also be argued that insufficient statistical power and inability of the data collection tools to detect change could explain the lack of results, nevertheless, the sample was large enough to observe significant differences between the groups initially, and findings from the post-survey questionnaire support the conclusion that no changes occurred for the majority of gardeners during the year. Fifth, to avoid overburdening participants, we decided not to record dining out food purchase data. Nevertheless, despite shifts in eating patterns favouring eating out, French food consumption is still mainly driven by household food purchases [69]. Sixth, knowing that changes in diet take time, a follow-up longer than 1 year might be needed to detect a change in food practices. However, given the high turnover in Montpellier gardens (gardeners quitting, moving, etc.), a longer follow-up would have resulted in important attrition, selection bias and loss of statistical power.

\section{Conclusions}

Our study did not find a positive impact of participation in a community garden on the sustainability of lifestyles. The qualitative evaluation identified difficulties encountered by the gardeners such as lack of time and insufficient gardening knowledge, as well as health problems and conflicts with other gardeners, thereby providing leads to identify solutions to overcome these barriers. At a time when many cities are planning to establish community gardens on their territories, our findings call on public authorities and gardening leaders to rethink the management and organisation of gardens. In light of our results, the establishment of gardens in the immediate vicinity of housing could facilitate a more regular use of the gardens. The presence of facilitators who supervise the garden, assist gardeners, promote group dynamics and serve as a mediator in conflict management could also favour the integration and long-term participation of individuals with a variety of cultural and socioeconomic profiles. An evaluation of these new gardening formats through future intervention studies may provide evidence of the relevance of using community gardens to accompany the urban population towards the adoption of more sustainable lifestyles.

\section{Supplementary Information}

The online version contains supplementary material available at https://doi. org/10.1186/s12889-020-09836-6.

Additional file 1. Data analyses of food supply diary and accelerometer.

Additional file 2. Additional information from the online questionnaire of the JArDinS study.

Additional file 3. Group differences and time effect of lifestyles components among active gardeners ( $\geq 1$ visit per month throughout the year, $n=37$ ) and paired non-gardeners.

Additional file 4. Group differences and time effect of lifestyles components of gardeners who did not dropped out the garden during the year $(n=50)$ and paired non-gardeners.

\section{Acknowledgements}

We would like to thank the Montpellier department of lanscape and biodiversity, local garden networks (Semeurs de Jardins, APIEU) and the associations in charge of organizing and managing community gardens in Montpellier who facilitated the recruitment process, as well as the study participants for their time and involvement in the study. We thank the team of the Surfood-Foodscape project, especially Pascale Scheromm, Christophe Soulard, Nicolas Bricas, Simon Vonthron for their comments and suggestions. We also would like to thank Maël Garnotel for assisting in the use of the accelerometers.

\section{Authors' contributions}

ND supervised the study. ND, CM, MP and MT designed the JArDinS study. MT and MP were in charge of the investigation and collected data. Under the supervision of $J \mathrm{~L}, \mathrm{AS}$ collected and analysed data from the in-depth interviews. MT wrote the first draft of the manuscript. All authors proposed critical comments and approved the manuscript for publication. The author(s) read and approved the final manuscript.

\section{Funding}

This research was part of the Surfood-Foodscape project. This work was publicly funded through ANR (the French National Research Agency) under the "Investissements d'avenir" programme, reference ANR-10-LABX-001-01 Labex Agro, and coordinated by the Agropolis Foundation. It was also supported by the Olga Triballat Institute. The funders had no role in the design of the study or the collection, analysis and interpretation of data, or in writing the manuscript.

\section{Availability of data and materials}

The data that support the findings of this study are available from MT but restrictions apply to the availability of these data, which were used under license for the current study, and so are not publicly available. Data are however available from the authors upon reasonable request and with permission of data controller (CM) and interested parties.

\section{Ethics approval and consent to participate}

All subjects received an information letter describing the purpose and the procedures of this study, as well as participant's right and data confidentiality before they participated in the study. A verbal consent was given by each participant, following recommendation of the Research Ethics Committee. The study was conducted in accordance with the Declaration of Helsinki, and the protocol was approved by the Ethics Committee of the French Institute for Health and Medical Research and the Commission Nationale Informatique et Libertés (IRB00003888). The JArDinS study was registered at clinicaltrials.gov as NCT03694782. 


\section{Consent for publication}

Not applicable.

\section{Competing interests}

Not applicable.

\section{Author details}

'MOISA, Univ Montpellier, CIRAD, CIHEAM-IAMM, INRAE, Institut Agro, Montpellier, France. ${ }^{2}$ University of Colorado Boulder, Boulder, CO, USA. ${ }^{3}$ CarMen Laboratory, INSERM 1060, INRA 1397, University of Lyon, F-69600 Oullins, France. ${ }^{4}$ ISGlobal, Barcelona, Spain.

Received: 5 August 2020 Accepted: 4 November 2020 Published online: 26 November 2020

\section{References}

1. Soga M, Gaston KJ, Yamaura Y. Gardening is beneficial for health: a metaanalysis. Prev Med Rep. 2017;5:92.

2. Savoie-Roskos MR, Wengreen $H$, Durward C. Increasing fruit and vegetable intake among children and youth through gardening-based interventions: a systematic review. J Acad Nutr Diet. 2017;117:240-50.

3. Rochira A, Tedesco D, Ubiali A, Fantini MP, Gori D. School gardening activities aimed at obesity prevention improve body mass index and waist circumference parameters in school-aged children: a systematic review and meta-analysis. Child Obes. 2020;16:154-73.

4. Clatworthy J, Hinds JM, Camic P. Gardening as a mental health intervention: a review. Ment Health Rev J. 2013;18:214-25.

5. Uwajeh PC, lyendo TO, Polay M. Therapeutic gardens as a design approach for optimising the healing environment of patients with Alzheimer's disease and other dementias: a narrative review. Explore. 2019;15(5):352-62.

6. Pourias J, Duchemin E, Aubry C. Products from urban collective gardens: food for thought or for consumption? Insights from Paris and Montreal. J Agric Food Syst Commun Dev. 2015:5(2):1-25.

7. Crouch D, Ward C. The allotment: its landscape and culture. 3rd ed. Nottingham: Five Leaves Publications; 1997.

8. Archer JE. The nineteenth-century allotment: half an acre and a row. Econ Hist Rev. 1997:50:21-36.

9. Kurtz H. Differentiating multiple meanings of garden and community. Urban Geogr. 2001;22:656-70.

10. Alaimo K, Beavers AW, Crawford C, Snyder EH, Litt JS. Amplifying health through community gardens: a framework for advancing multicomponent, behaviorally basedneighborhood interventions. Curr Environ Health Rep. 2016:3:302-12.

11. Alaimo K, Packnett $E$, Miles RA, Kruger DJ. Fruit and vegetable intake among urban community gardeners. J Nutr Educ Behav. 2008;40:94-101.

12. Booth JM, Chapman D, Ohmer ML, Wei K. Examining the relationship between level of participation in community gardens and their multiple functions. J Community Pract. 2018:26:5-22.

13. Litt JS, Soobader M-J, Turbin MS, Hale JW, Buchenau M, Marshall JA. The influence of social involvement, neighborhood aesthetics, and community garden participation on fruit and vegetable consumption. Am J Public Health. 2011;101:1466.

14. Litt JS, Schmiege SJ, Hale JW, Buchenau M, Sancar F. Exploring ecological, emotional and social levers of self-rated health for urban gardeners and non-gardeners: a path analysis. Soc Sci Med. 2015;144:1-8.

15. Machida D. Relationship between community or home gardening and health of the elderly: a web-based cross-sectional survey in Japan. Int J Environ Res Public Health. 2019;16:1389.

16. Zick CD, Smith KR, Kowaleski-Jones L, Uno C, Merrill BJ. Harvesting more than vegetables: the potential weight control benefits of community gardening. Am J Public Health. 2013;103:1110-5.

17. Litt JS, Lambert JR, Glueck DH. Gardening and age-related weight gain: results from a cross-sectional survey of Denver residents. Prev Med Rep. 2017;8:221-5.

18. Algert SJ, Diekmann L, Renvall M, Gray L. Community and home gardens increase vegetable intake and food security of residents in San Jose, California. Calif Agric. 2016;70:77-82

19. Comstock N, Miriam Dickinson L, Marshall JA, Soobader M-J, Turbin MS, Buchenau M, Litt JS. Neighborhood attachment and its correlates: exploring neighborhood conditions, collective efficacy, and gardening. J Environ Psychol. 2010;30:435-42.
20. Alaimo K, Reischl TM, Allen JO. Community gardening, neighborhood meetings, and social capital. J Community Psychol. 2010;38:497-514.

21. Draper C, Freedman D. Review and analysis of the benefits, purposes, and motivations associated with community gardening in the United States. J Community Pract. 2010;18:458-92.

22. Demark-Wahnefried W, Cases MG, Cantor AB, Frugé AD, Smith KP, Locher J, Cohen HJ, Tsuruta Y, Daniel M, Kala R, et al. Pilot randomized controlled tria of a home vegetable gardening intervention among older cancer survivors shows feasibility, satisfaction, and promise in improving vegetable and fruit consumption, reassurance of worth, and the trajectory of central adiposity. J Acad Nutr Diet. 2018:118:689-704.

23. Litt JS, Alaimo K, Buchenau M, Villalobos A, Glueck DH, Crume T, Fahnestock L, Hamman RF, Hebert JR, Hurley TG, et al. Rationale and design for the community activation for prevention study (CAPs): a randomized controlled trial of community gardening. Contemp Clin Trials. 2018:68:72-8.

24. Porter CM, Wechsler AM, Hime SJ, Naschold F. Adult health status among native american families participating in the growing resilience home garden study. Prev Chronic Dis. 2019;16:190021.

25. Landry M, Asigbee F, Vandyousefi S, Jeans M, Ghaddar R, Hoelscher D, Van Den Berg A, Davis J. Effects of TX sprouts, a school-based cluster randomized gardening, nutrition, and cooking intervention, on dietary quality. Curr Dev Nutr. 2020;4:1321

26. Benjamin-Neelon S, Liu T, Puffer ES, Turner L, Zaltz D, Thorne-Lyman A, Broverman S. A garden-based intervention to improve dietary diversity in Kenyan school children: results from a natural experiment. Curr Dev Nutr. 2020:4:810.

27. Akenji L, Chen $\mathrm{H}$. A framework for shaping sustainable lifestyles: determinants and strategies. Nairobi: United Nations Environment Programme; 2016

28. Turner B. Embodied connections: sustainability, food systems and community gardens. Local Environ. 2011;16:509-22.

29. Algert SJ, Baameur A, Renvall MJ. Vegetable output and cost savings of community gardens in San Jose, California. J Acad Nutr Diet. 2014;114: 1072-6.

30. Martin P, Consalès J-N, Scheromm P, Marchand P, Ghestem F, Darmon N. Community gardening in poor neighborhoods in France: a way to re-think food practices? Appetite. 2017;116:589-98.

31. World Commission on Environment and Development. Our common future. Oxford: World Commission on Environment and Development; 1897.

32. Frohlich $\mathrm{KL}$, Corin $\mathrm{E}$, Potvin $\mathrm{L}$. A theoretical proposal for the relationship between context and disease. Sociol Health IIIn. 2001;23:776-97.

33. Tharrey M, Perignon M, Scheromm P, Mejean C, Darmon N. Does participating in community gardens promote sustainable lifestyles in urban settings? Design and protocol of the JArDinS study. BMC Public Health. 2019:19:589.

34. Maillot M, Darmon N, Vieux F, Drewnowski A. Low energy density and high nutritional quality are each associated with higher diet costs in French adults. Am J Clin Nutr. 2007;86:690-6.

35. Vieux F, Soler L-G, Touazi D, Darmon N. High nutritional quality is not associated with low greenhouse gas emissions in self-selected diets of French adults. Am J Clin Nutr. 2013;97:569-83.

36. Tharrey M, Dubois C, Maillot M, Vieux F, Méjean C, Perignon M, Darmon N. Development of the healthy purchase index (HPI): a scoring system to assess the nutritional quality of household food purchases. Public Health Nutr. 2019:22:765-75.

37. Garnotel M, Bastian T, Romero-Ugalde H-M, Maire A, Dugas J, Zahariev A, Doron $M$, Jallon P, Charpentier G, Franc S, et al. Prior automatic posture and activity identification improves physical activity energy expenditure prediction from hip-worn triaxial accelerometry. J Appl Physiol. 2018;124: 780-90.

38. Tennant R, Hiller L, Fishwick R, Platt S, Joseph S, Weich S, Parkinson J, Secker J, Stewart-Brown S. The Warwick-Edinburgh mental well-being scale (WEMWBS): development and UK validation. Health Qual Life Outcomes. 2007;5:63.

39. Russell DW. UCLA loneliness scale (version 3): reliability, validity, and factor structure. J Pers Assess. 1996:66:20-40.

40. Le Borgne G, Sirieix L, Costa S. Perceived probability of food waste: influence on consumer attitudes towards and choice of sales promotions. J Retail Consum Serv Pergamon. 2018;42:11-21.

41. Nisbet EK, Zelenski JM, Murphy SA. The nature relatedness scale. Environ Behav. 2009;41:715-40 
42. Hart CM, Ritchie TD, Hepper EG, Gebauer JE. The balanced inventory of desirable responding short form (BIDR-16). SAGE Open. 2015;5: 215824401562111.

43. ATLAS.ti [Computer software]. 2020. Available from: https://atlasti.com/.

44. Richards L. Handling qualitative data: a practical guide. Thousand Oaks: Sage; 2014. p. 236

45. Guitart D, Pickering C, Byrne J. Past results and future directions in urban community gardens research. Urban For Urban Green. 2012;11:364-73.

46. Malberg Dyg P, Christensen S, Peterson CJ. Community gardens and wellbeing amongst vulnerable populations: a thematic review. Health Promot Int. 2019:35:790-803.

47. Coughlin SS. Recall bias in epidemiologic studies. J Clin Epidemiol 1990:43:87-91.

48. Kim DJ, Holowaty EJ. Brief, validated survey instruments for the measurement of fruit and vegetable intakes in adults: a review. Prev Med. 2003;36:440-7

49. French SA, Shimotsu ST, Wall M, Gerlach AF. Capturing the spectrum of household food and beverage purchasing behavior: a review. J Am Diet Assoc. 2008;108:2051-8.

50. Shephard RJ, Vuillemin A. Limits to the measurement of habitual physical activity by questionnaires. Br J Sports Med. 2003;37:197-206.

51. Hills AP, Mokhtar N, Byrne NM. Assessment of physical activity and energy expenditure: an overview of objective measures. Front Nutr. 2014;1:5.

52. Zhao Y, Liu Y, Wang Z. Effectiveness of horticultural therapy in people with dementia: a quantitative systematic review. J Clin Nurs. 2020. https://doi. org/10.1111/jocn.15204

53. Genter C, Roberts A, Richardson J, Sheaff M. The contribution of allotment gardening to health and wellbeing: a systematic review of the literature. $B$ J Occup Ther. 2015;78:593-605.

54. Frumkin H, Bratman GN, Breslow SJ, Cochran B, Kahn PH, Lawler JJ, Levin PS, Tandon PS, Varanasi U, Wolf KL, et al. Nature contact and human health: a research agenda. Environ Health Perspect National Institute of Environmental Health Science. 2017;125:075001.

55. Hale J, Knapp C, Bardwell L, Buchenau M, Marshall J, Sancar F, Litt JS. Connecting food environments and health through the relational nature of aesthetics: gaining insight through the community gardening experience. Soc Sci Med. 2011;72:1853-63.

56. Lake B, Milfont T, Gavin M. The relative influence of psycho-social factors on urban edible gardening. N Z J Psychol. 2012;41:49-58.

57. Wise P. Grow your own: the potential value and impacts of residential and community food gardening. Policy Brief No. 59. Canberra; 2014.

58. Loopstra R, Tarasuk V. Perspectives on community gardens, community kitchens and the good food box program in a community-based sample of low-income families. Can J Public Health. 2013;104:e55-9.

59. Ornelas IJ, Osterbauer K, Woo L, Bishop SK, Deschenie D, Beresford SAA, Lombard K. Gardening for health: patterns of gardening and fruit and vegetable consumption among the Navajo. J Community Health. 2018;43: 1053-60.

60. Morland K, Diez Roux AV, Wing S. Supermarkets, other food stores, and obesity: the atherosclerosis risk in communities study. Am J Prev Med. 2006; 30:333-9.

61. Gordon-Larsen P, Nelson MC, Page P, Popkin BM. Inequality in the built environment underlies key health disparities in physical activity and obesity. Pediatrics. 2006;117:417-24.

62. Kirkpatrick SI, Tarasuk V. Food insecurity and participation in community food programs among low-income Toronto families. Can J Public Health. 2009;100:135-9.

63. Mozaffarian D, Hao T, Rimm EB, Willett WC, Hu FB. Changes in diet and lifestyle and long-term weight gain in women and men. N Engl J Med. 2011:364:2392-404.

64. Shadish WR, Cook TD, Campbell DT. Experimental and quasi-experimental designs for generalized causal inference: Wadsworth Cengage Learning. Boston: Houghton Mifflin Company; 2002. p. 623.

65. Petticrew M, Cummins S, Ferrell C, Findlay A, Higgins C, Hoy C, Kearns A, Sparks L. Natural experiments: an underused tool for public health? Public Health. 2005;119:751-7.

66. Leatherdale ST. Natural experiment methodology for research: a review of how different methods can support real-world research. Int J Soc Res Methodol. 2019;22:19-35.

67. Rothman KJ, Greenland S, Lash TL. Modern epidemiology: third edition. Philadelphia: Lippincott Williams \& Wilkins; 2008. p. 776.
68. ANSES. Étude individuelle nationale des consommations alimentaires 3 (INCA 3). Avis de l'Anses. Rapport d'expertise collective. 2017.

69. Volatier J-L. Enquête INCA (enquête individuelle et nationale sur les consommations alimentaires, Collection AFSSA) VOLATIER Jean-Luc. Paris; 2000.

\section{Publisher's Note}

Springer Nature remains neutral with regard to jurisdictional claims in published maps and institutional affiliations.
Ready to submit your research? Choose BMC and benefit from:

- fast, convenient online submission

- thorough peer review by experienced researchers in your field

- rapid publication on acceptance

- support for research data, including large and complex data types

- gold Open Access which fosters wider collaboration and increased citations

- maximum visibility for your research: over $100 \mathrm{M}$ website views per year

At BMC, research is always in progress.

Learn more biomedcentral.com/submissions 